In the history of many other epidemics we fease commenced during the day, and lasted find coincidences of this deseription of pe- four-and-twenty hours. The respiration culiar diseases affecting the lower animals, was short and hurried, the motions of the while pestilences were decimating man- heart accelerated, and diminished in force kind. Sometimes horned cattle, at other in proportion to their increase in velocity, times horses, have been especially attacked; In almost every instance there had been but there have not been recorded more than numerous whitish liquid dejections. The two or three examples of epizootics among gullet was distended with thready mucus, birds. Chabert and Boronio hare, it is which escaped from the beak. The combs true, described some diseases of birds, ob- were of a livid red colour, and the tint served in France and in Lombardy, but the deepened to a violet as death drew near. characters of the affections they describe are totally different from those observed at Choisi.

The cholera had scarcely appeared at Paris, when it was generally reported that a disease of most destructive mortality was raging among the poultry throughout the commune. Here, as at Paris, the cry of " poisoning" was loudly made; all persons who were persuaded that the food and drink of mankind were mixed with poison, found no difficulty in convincing themselves that similar villany was practised in the poultry yards. But the mortality soon reached such a pitch, that this idea was abandoned, and then it was generally reported, that the cholera was the cause of the epizootic.

Wishing to arrive at the source of these rumours, I learned, that since the 3rd of April, a vast number of fowls had perished in several houses situated in different quarters of the hamlet. During the first days of the disease, the number of deaths had been very considerable, after which period the birds were killed by the owners on the occurrence of the first symptoms. In one fowl-yard, of eighty cases, one or two alone recovered. Many remedies, amongst others bleeding under the wings, had been in vain resorted to. A considerable quantity of the diseased fowl had been eaten by the in. habitants without any bad effect.

'The causes of this malady appear to me altogether unknown, and $I$ saw no reason for supposing it to be contagious. Nevertheless, when a single death occurred in a fowl-yard, the mortality only ceased when it had no more victims to destroy. The most cleanly poultry feeders suffered as severely as the most filthy. The kind of food had no influence on the disease. The fowls at large in the streets of Choisi were attacked with equal severity with those perpetually confined or occupied in incubation. Ralbits, geese, and ducks, however, lived with impunity in the same yards where the hens were universally perishing, and three turkeys only were affected.

The disease, generally speaking, commenced in the morning. The hens were noticed to be dull and weak, their wings drooping, and their crops distended with undigested food. In a few cases the dis-

After the disease had lasted from two to five hours, convulsions usually finished the sufferings of the animal, and death was rapid in proportion to the quantity of the evacuations. In many cases I have learned, that the coldness of the sick birds was very remarkable. A few recoveries were noticed towards the termination of the epizootic. As far as I can find out, about 500 fowls died of the disease, or were lilled in consequence of the development of its symptoms.

After death the colour of the skin was the same as in fowls strangled without being bled. The bodies were warm for at least three hours, and the cadaveric rigidity was very remarkable.

I have taken much pains in seeking for any pathological alterations which might explain the cause of the disease, but my research was quite in vain. The brain was white, and free from congestion. The heart was bloodless, and of its usual consistence. The aorta contained fluid blood. The lungs were rosy and crepitating. The mucous membrane of the resophagus frequently showed little papillæ, surmounted here and there with a white point, like a minute grain of sand, adhering to the centre of the papilla. The crop always contained food; the gizzard was strongly contracted; the intestine presented occasional reddish patches, especially in the situations where little parcels of worms were found. The liver was gorged with black and tarry blood; the gall-bladder distended with thick green bile.

This epizootic is quite different from the " maladie charbonneuse" of Clabert, and from that described by Boronio. Neither has it any analogy to the "pip," for the tongue was always in a natural state.Journal Hebdomadaire.

DISCOVERY OF

\section{AIR IN THE HEART}

AFTER VENOUS INJECTION.

To the Editor of The Lancet.

Sir,-The interest excited by the ex. periments performed in London, of the introduction of saline substances in the fluid 
state into the blood of patients labouring under cholera, has not been lessened by the result of the trials recently /made by Dr. Venables, and other practitioners, without success. The post-mortem appearances in two individuals treated in this manner under the superintendence of Dr. Venables, have been fully detailed in the last number of THE LANCET. In both, air was found in some quantity in the cavities of the heart. This circumstance has been supposed by many to account in a satisfactory manner for the patient's death, but I have been assured by Dr. Venables, (and I can place full reliance on his capacity for conducting the operation, and the veracity of his report,) that every care was taken to exclude the access of atmospheric air, not a particle of which was introduced in the course of the operation. That, however, air may be generated spontaneously in the heart, was proved to me yesterday while examining the body of a cholera patient. Mrs. R., the wife of a man in poor circumstances, died of this disease on Sunday last, July 1st, after twelve hours illness. On the following Wednesday, at noon, I assisted my friend, Dr. Hingeston, of the South London Infirmary, in inspecting the body. The general anatomical appearances were those which I have invariably found, but the contents of the stomach and intestines were acid (the woman had been strongly purged). The heart was soft and distended, and when a puncture was made into it, a good deal of air escaped, followed by fluid blood mixed with bubbles of air. The treatment consisted in the exhibition of calomel, Cayenne pepper, and other stimulants in a fluid form. I do not remember to have seen so great a quantity of air in the heart so soon after death in any other instance. I submit the question whether the peculiar condition of the blood could have influenced this early separation of gas in the case of this woman. I am, Sir, your obedient servant,

July 4th, 1832.

\section{DR, JOHNSON AND DR. RAMADGE.}

\section{To the Editor of The Lancer.}

Str,--The character of that worthy " Fellow" and associate of St. John Long, both of whom you so well castigated in the Court of Common Pleas, is illustrated by the following facts, which the Doctor and his counsel tried hard to couple together as cause and effect, to weaken my testimony on the late trial. When I first settled in London, and before I was admitted by the College of Physicians, Dr. Ramadge and myself came into consultation in the Strand, and the learned and experienced "Fellow" expressed great apprebension lest he should be censured by the College of Physicians, if he were known to consult with me prior to my admission by that body! He, however, waived the objection when there appeared some danger of losing a fee by being too scrupulous of his honour and dignity. The matter occasioned no quarrel, and never induced an angry feeling on my part, though $\dot{I}$ often related the anecdote as an illustration of the Doctor's punctilious adhesion to professional etiquette. More than seven years afterwards, the learned Doctor took an opportunity, in my absence, to impugn some statement of a case which I had related in the London Medical Society; but at the next meeting, when I confronted him, he retracted his insinuations, and I fully proved the truth of my former statement. Who would imagine that Dr. Ramadge and his counsel would have the hardihood to couple these two occurrences together, and attempt to prove that Dr. Ramadge refused to consult with me in 1819 or 1820 , in consequence of his having accused me of making false statements of a case in 1827 or 1828? Yet such they did attempt to do, till I exposed the falsity of their assumptions.

$$
\text { I am, Sir, }
$$

Your obedient servant, James Johnson.

Suffolk Place, Pall Mall, June 28, 1832.*

\section{ST. THOMAS'S HOSPITAL.}

TREATMENT OF VOMITING BY THE ADMINISTRATION OF HYDROCYANIC ACID.

TII following case possesses interest for two reasons, first, that after death nothing was found to account in any way for some of the symptoms present; and, secondly, as it affords another proof, if any such can be wanting, of the efficacy of the hydrocyanic acid in checking vomiting, which it has been shown to do in almost every case, from whatever cause arising. To bear us out in this statement, we have only to refer our readers to Dr. Elliotson's excellent work on the properties and uses of this acid, which supplies everything that is known on the subject.

John Pindar, æetat. 30, was admitted into William's Ward under the care of Dr. Elliotson on the 1st of March. He stated that he was stoker in a brewhouse, and had been in the daily habit of drinking large quantities of porter. Eighteen months since be

* Received too late for last week's Number, ED. 